www.jmscr.igmpublication.org

Impact Factor 5.84

Index Copernicus Value: 71.58

ISSN (e)-2347-176x ISSN (p) 2455-0450

crossref DOI: _https://dx.doi.org/10.18535/jmscr/v5i9.102

\title{
Closed vs Open Lateral Internal Sphincterotomy in Chronic Anal Fissure: A Randomized Study to Compare Post-Operative Complications and Results
}

\author{
Authors \\ Dr Akash Kumar Singh, Dr S B Prasad \\ NMCH Patna
}

\begin{abstract}
Objective \& Background: Basis of treatment of chronic anal fissure lies in decreasing spasm of internal anal sphincter. Open lateral internal sphincterotomy (OLIS) and Closed lateral internal sphincterotomy (CLIS) are two different methods for relaxing fibres of internal anal sphincter which result in healing of ulcer. These 2 methods have been compared in some previous research in terms of post operative complications i.e. pain, discharge, hospital stay, incontinence \& recurrence. This study was done to determine better method in terms of above complications.

Method: 100 patients with chronic anal fissure were randomly selected irrespective of age and gender and randomly allocated into group A and B.50 patients of group A underwent CLIS while 50 patients of group B underwent OLIS. Patients were followed up for 12 months after procedure. Results were compared in terms of pain, bleeding, infection, incontinence of flatus\& faeces and recurrence.

Result: Postoperative pain was reported more in OLIS group (12\%) as compared to CLIS group (8\%) $(p<0.001$ which is significant).Bleeding during defaecation in follow-up period was almost equal in OLIS group (6\%) as compared to 4\% in CLIS group. Temporary incontinence of flatus and faeces was $12 \%$ in OLIS vs $6 \%$ in CLIS ( $p<0.05)$.Recurrence was $14 \%$ in OLIS vs $16 \%$ in CLIS. Postoperative stay was average 2.5 days in CLIS group as compared to average 6 days in OLIS.

Conclusion: CLIS is a safe procedure in terms of lesser hospital stay, lesser post operative pain and least incontinence as compared to OLIS. It has an accepted rate of complications and should be adopted by experienced surgeons in the treatment of chronic anal fissure.

Keywords: OLIS; CLIS; sphincterotomy; fissure.
\end{abstract}

\section{Introduction}

Anal fissure causes substantial morbidity in healthy population. All the treatment modalities aimed at reducing anal sphincteric pressure that causes fissure healing and relief of pain \& bleeding symptoms. From ancient time some medical therapy (sphincter relaxant drugs)like GTN,NIFEDIPINE,LAXATIVE is in use. ${ }^{[1-4]}$ Their effect are appreciable but risk of late recurrence remains uncertain. History of surgical management starts from locally botulinum toxin to anal dilatation \& pneumatic ballon dilatation upto sphincterotomy ${ }^{[5-7]}$. Lateral internal sphincterotomy is very effective and safe procedure with lesser recurrence and least complications ${ }^{[8,9]}$. Open lateral internal sphincterotomy (OLIS) consists of radial incision ( 3 "O clock) at anoderm and cutting lower $1 / 3^{\text {rd }}$ of internal sphincter under 
vision while Closed lateral internal Sphincterotomy (CLIS) comprises division of internal sphincter by Von Greaves knife/cataract knife without making skin incision. Both the methods are better in terms of least post-operative pain and recurrence. Lateral internal sphincterotomy has some level of temporary incontinence postoperatively, with few patients having permanent incontinence of flatus and faeces ${ }^{[10-13]}$. In the recent time it has remained a matter of debate that which process is better. A few prospective analysis showed CLIS better than OLIS in terms of post operative complications. This study was done in Nalanda medical college Patna to compare these methods in terms of post-operative complications and results.

\section{Material \& Methods}

This was a double blinded prospective study done at general surgery department, Nalanda Medical college patna from jan 2011 to dec 2012 A total of 100 patients with chronic anal fissure were selected for the study.

\section{Sample Size}

100 patients with chronic anal fissure with no prior treatment were randomly allocated into two groups; Group A and Group B.50 patients in Group A underwent OLIS while other 50 patients in Group B were treated by CLIS.

\section{Inclusion Criteria}

Patients with chronic anal fissure between 20 to 60 yrs were randomly allocated into 2 groups. Patients were not treated prior to study.

\section{Exclusion Criteria}

Previous treated, crohn's disease, haemorrhoid patients were escluded from study.

\section{Ethical Issue}

Patients were informed about the procedure and the expected outcome. written informed consent were taken for the procedure.

\section{Methodology}

OLIS comprised of radial incision at intersphinctric groove and cutting of internal anal sphincter upto dntat line. Wound was left open to heal by secondary intention. CLIS was done with Von -
Greaves knife (cataract knife). knife was introduced in intersphinctric groove and turned inward thre to cut internal sphincter. There was no raw wound after this procedure. Patient were kept two to six days post-operatively. After getting discharged they were followed up every month upto 1 year.

\section{Observations}

Results were analyzed in terms of post-operative hospital stay, bleeding, pain, incontinence and recurrence.

Pain assessment scale based on visual analogue scale was used.post-operative pain was present in $12 \%$ of OLIS group patients as compared to $8 \%$ of CLIS group $(\mathrm{p}<0.001$ which is significant

Bleeding during defaecation was present in $6 \%$ of OLIS patients vs $4 \%$ of CLIS patients.

Temporary incontinence to flatus and faeces was present in $12 \%$ of OLIS patients vs $6 \%$ in CLIS(P $<0.05)$

Recurrence of symptoms was $14 \%$ in OLIS vs 16\% CLIS patients.

Postoperative stay in hospital was mean 6 days in OLIS group as compared to mean 3 days in CLIS .

\section{Conclusions}

Post-operative pain and bleeding was lesser in CLIS as compared to OLIS .This finding was in concordance with Shafiquallah and Nadeem at Nishtar hospital, Multan ( $8 \%$ vs $4 \%$ ) for pain and (4\% VS $0 \%$ ) for bleeding. ${ }^{[14]}$

Temporary incontinence was significantly lesser $6 \%$ in CLIS as compred to $12 \%$ in OLIS.

However manometric study could have done for exact validation.

A retrospective study at Valencia, spain (2008) had similar incontinence rate.

Recurrence was equivocal in both groups. Naveed Ahmed et al at Nishtar hospital also found $12 \%$ vs $12 \%$ recurrence. ${ }^{[15]}$

Post-operative stay was significantly lesser in patients treated by CLIS.

Both treatments aimed at reducing resting anal sphincteric pressure. Result of the treatments was 
based on invasiveness of the procedure. OLIS little bit more invasive is associated with more post-operative pain, bleeding and incontinence. While CLIS less invasive is associated with lesser bleeding, pain and incontinence. Hence it was concluded that CLIS is better procedure than OLIS in terms of post-operative complications \& results.

\section{Ethical Statement}

Study was approved by department of surgery, Nalanda medical college, patna. All procedures performed in the study involving human participant were in accordance with ethical standard of the institution and with the 1964 Helinski declaration and its later amendments.

\section{References}

1. Amir Amanullah (2008); Pakistan J.Med. Research, vol.24,issue-4

2. M.Wiley(2004);Disease of colon and rectum,vol.47; No.6,847-52

3. 3.Gupta PJ(2007);Am.j.surgery,194(1);136

4. Renzi.A.(2008);Disease of colon and rectum 51(1);121-7

5. Bailey \& Love's short practice of surgery $24^{\text {th }}$ ed:p. $1252-54$

6. Marion J;Anal fissure and chemical sphincterotomy

7. Samual S.anal fissure In Mazien wp Lein DH, Luchfeld MA ,Senagre AG,Surgery of colon \& rectum 1995,p.255-68

8. Mataros MJ; Lateral subcutaneous internal anal sphincterotomy for anal fissure. In: Dudley H. $3^{\text {rd }}$ ed:chapman \&Hall medical; 1996 p.848

9. Milito G.subcutaneous lateral internal sphincterotomy Ital J Surg sciences 1983;13:275-79

10. Hawley PR.The treatment of chronic fissure-in-ano: A trial of methods. Br J Surg 1969;56:915-18
11. Bennet RC. Results of internal sphincterotomy for anal fissure.Br Med J 1962;5318;1500-03

12. Prohm P.Dis.Colon Rectum.1995 Jul;38(7);753-8

13. Kennedy ML.Dis Colon and Rectum.1999 Aug ; 42(8) 1000-6

14. Shafiquallah (2004); Pakistan J.Med. Research vol.43,No.1

15. Naveen Ahmad (2005); The Proffesional, vol-12,no.1. 